A. H. Tubby, Messrs R. J. Coulter, R. Jagues, G. H. Pooley, E. Park-Lewis, A. S. Percival, Angus MacGillivray and LISTER LLEWELLYN.

On the afternoon of Thursday, a garden party had been arranged in the Gardens of University College but owing to the weather the members of the Congress and their friends were received in the Hall of the College. Dr. Ainley Walker, Dean of the Medical Faculty of the University, and Mrs. Walker acted as host and hostess.

The Annual Dinner of the Congress was held on the same day in the Hall of Keble College and was well attended, amongst those present being Sir T. Herbert Warren, The President of Magdalen College, Dr. Ainley Walker, Dr. de Schweinitz, Sir George BerRy, M.P., Dr. Gibson, Dr. Howard F. Hansell, Dr. Park Lewis and Professor Friedenwald.

No meeting of the Congress will take place in 1925 on account of the Convention of English-Speaking Ophthalmological Societies which will be held in London in July of that year.

\title{
ANNOTATIONS
}

\section{Ocular Palsies in Encephalitis Lethargica}

The diagnosis of the cause of the more obscure cases of ocular palsy is never an easy one. Encephalitis lethargica, especially in its milder forms, is one of the less common causes. Dr. C. W. Yow, in a recent communication to the Lancet, (June 21, 1924), has given an analysis of the cases of diplopia seen at the Royal Eye Hospital, from the beginning of the year to the end of May, amongst which were 21 undoubted cases of encephalitis all with a history of diplopia. There was a marked increase of the number of cases of diplopia in the month of April which is attributed by the author to a coincident increase in the number of cases of encephalitis.

We do not think that there is any risk of this cause of ocular palsy being overlooked by the profession, the tendency is rather the other way. Cases of serious intracranial disease such as cyst of the cerebellum, temporo-sphenoidal tumour, tuberculous meningitis etc., have recently come under our notice wrongly diagnosed as encephalitis lethargica, mainly on account of the presence of oculo-motor paralysis. 